\title{
GUIDELINES FOR AUTHORS
}

1. The annual journal Belarusian Studies encourages submissions of previously unpublished scholarly articles. The submission of an article to the journal indicates the author's consent to its publication both on paper and in electronic form on the journal's website (http://journals.umcs.pl/sb).

2. The journal Belarusian Studies contains materials in Polish, Belarusian and the following congress languages: Russian, English, and German.

3. Materials for publication should be submitted in electronic form via the UMCS Journal Platform, following registration at: journals.umcs.pl/sb. The articles submitted should be written in a common word processor, preferably in newer versions of Microsoft Word for Windows. In the case of less common editors, an RTF file should also be attached. The text should be written with the automatic hyphenation function switched off and without non-breakable spaces. Font format: Times New Roman, size 12, line spacing 1.5. The page number should be placed at the bottom of the page, centred under the text. If the text contains unusual fonts, attach them as auxiliary files. Drawings, charts, tables, photographs should be submitted as separate files. The layout of the illustrations must be indicated in the text.

4. Please adhere to the following order:

Author (first and last name): in original language and transcribed into English in the case of Eastern scripts (official transcription from passport).

Affiliation: in Polish and English.

E-mail address.

ORCID.

Title in original language, English, Polish, and Belarusian (if English, Polish or Belarusian is the original language, it should appear first).

Abstracts and keywords (3-5) in English, Polish, and Belarusian.

Text.

Bibliography (in the following order: bibliography of primary sources, bibliography of secondary sources, as in the APA style guidelines).

5. In reviews, the text should be preceded with information (in bold) on the work being reviewed [first and last name of author, title (in italics), publishing house, year and place of publication, number of pages]. The first and last name of the author of the review is placed under the text (in italics, on the right side). The same principle applies to book notes. 
6. In conference reports, the text should be preceded with the title of the conference (text font), as well as its date (day, month, year) and location. The first and last name of the author of the report is placed under the text (in italics, on the right side).

7. The following information on the author should be submitted with the text (as an auxiliary file): first and last name, academic degree and title, place of work (university or other institution, chair/department, position, address), e-mail (preferably official), mailing address, major subject, academic interests, and list of five most important publications. The submission of personal data indicates the author's consent to its publication both on paper and in electronic form.

8. Length of articles and review articles (contains bibliographical references and is subject to a review process): not less than half a publisher's sheet (20 000 characters incl. spaces) and not more than one publisher's sheet (40 000 characters incl. spaces). When calculating the length of the article, take into account all the elements listed in point 3, as well as tables, charts and photographs. Length of analytical reviews: not more than 10000 characters. Length of book notes: not more than 4000 characters; length of conference reports and biographies: not more than 6000 characters.

9. Short citations are enclosed in quotation marks, longer ones (more than 3 lines) are distinguished graphically using a $10 \mathrm{pt}$ font, single line spacing.

10. Date format: 12.11 .2016 , for old/new style dates: 27.03/8.03.1896.

11. Centuries should be written as two-digit numbers: the $19^{\text {th }}$ century. Decades should be written as four-digit numbers: the 1960s.

12. Latin abbreviations should be kept out of the main body of the text. They should not be italicized.

13. When referencing an institution for the first time, provide its full name along with the acronym; use only the acronym thereafter. Example: The Central Citizens' Committee (Centralny Komitet Obywatelski, CKO) was established in Petrograd in 1915. In the following years, CKO members were engaged in aid activities in Russia.

14. In the case of commonly used acronyms (e.g. USSR, NKVD, KGB, BNP) the full name is not required.

15. The use of footnotes (10 pt, single spacing) should be limited; use them only for additional information that broadens the subject. Bibliographic references related to source literature are placed within the text in line with the APA style guidelines.

16. The texts submitted to the journal Belarusian Studies must be grammatically correct and follow the requirements laid down by the Editorial Board. The texts not conforming to these requirements will not be accepted for publication.

17. Failure by the author to respond to the Editorial Board's request to provide the data necessary for publication or to modify the text, as well as failure to carry out an author's correction within the given deadline will be equivalent to withholding the text from publication.

18. The authors of the articles published in the journal Belarusian Studies will receive 1 copy of the issue free of charge. 
19. The author of the publication shall be responsible for any liability arising from copyrights and publishing rights.

20. All forms of plagiarism and autoplagiarism will be viewed by the Editorial Staff as academic misconduct. The Editorial Staff will document and notify the relevant institutions of any breach or violation of the ethical rules pertaining to scholarly activity.

21. A completed and signed copy of the agreement between the Publishing House and the author of the publication must be delivered before the publication of the text.

\section{APA-style referencing:}

1. Guidelines for citing publications in the text:

a) one author: each time the work is referenced, the last name of the author and the year of publication must be given; when the author has published more than one cited work in the same year, these are distinguished by adding lower case letters to the year (2015a, 2015b). This principle also applies when the work in question has more than one author.

According to Dacewicz (2014, p. 23)...

The research shows that... (Mal'dzìs, 1992, p. 34).

b) two authors: each time the work is referenced, the last names of both authors and the year of publication must be given; when the authors have published more than one cited work in the same year, these are distinguished by adding lower case letters to the year; the names of the authors are separated by the word and when included in a sentence.

According to Kowalski and Nowak (1978, p. 98)...

The research a shows that... (Grzegorczykowa and Puzynina, 1999, pp. 78-98).

c) 3 authors: the last names of all authors must be given at the first reference, separated by commas and the word and between the last two names; for subsequent citations of the same work, the term ,and colleagues" may be used (when included in a sentence) or ,et al.” (when not included in a sentence).

First reference:

According to Baczyński, Celiński, and Dakowski (1999, p. 78)...

The researchs (Baczyński, Celiński and Dakowski, 2003, p. 98) show that...

Subsequent references:

The research by Baczyński and colleagues (2003, pp. 99-109) shows that...

This research (Baczyński et al., pp. 67-75)... 
d) 4 and more authors: only the last name of the first author must be given at the first reference and all subsequent ones alike, while the other authors should be identified as "colleagues" (when included in a sentence) or replaced with the abbreviation „et al." (when not included in a sentence); the names of all authors should however be included in the bibliography.

Grzegorzewski and colleagues claim that... (1997, p. 78);

The first research on this subject (Grzegorzewski et al., 1997, p. 43) suggests...

e) simultaneous referencing of several works: these should be listed in alphabetical order under the first author's last name; subsequent mentions should be separated by a semicolon and placed in parentheses; the years of publication of works by the same author(s) should be separated by a comma.

(Kowalczyk, 2005, p. 67; Nowaczek and Kowalczyk, 2008, pp. 78-98);

(Kowalczyk, 1995, 1999, 2007a, 2007b; Nowaczek and Kowalczyk, 2008).

f) References to sources within other sources should only be used in the body of the text. The primary source is identified in the text, whereas the bibliography contains only the secondary source.

According to Kozłowski (1991; as cited in Sarnowski, 2008, p. 34)...

The research shows that... (Kozłowski, 1991; as cited in Sarnowski, 2008, p. 78).

g) Works with no author: indicate the title of the work (books and dictionaries in italics; articles, chapters, and websites in quotation marks). If the title is long, it can be shortened (first 3 words).

As found by Belarusian linguists (Modern Belarusian linguistics, 2017, p. 42).

h) Press publication - author of the publication or the title, year of publication.

(W Mińsku, 1917).

i) Archival materials - name of the archive, signature, pages and title of the document (optionally).

In the writings of refugees (AAN, CKO, 11, p. 11, Raport...). 


\section{APA-style bibliography:}

Bibliography: the list should only contain the works referenced or cited that have actually been used by the author; the bibliography should not contain sources found within other sources. Do not use bulleted nor numbered lists; each work should be listed as a separate paragraph. The works must be arranged in alphabetical order by the last name of the first author. The works by the same author must be arranged in alphabetical order by their titles. The bibliographic list should be divided into two parts, i.e. primary and secondary sources. References in Cyrillic must be transliterated system ISO 9 into the Latin script and in original (in round brackets) [...].

Examples:

a) Book with a single author: Batowski, Henryk. (1988). Między dwiema wojnami 1919-1939. Zarys historii dyplomatycznej. Kraków: Wydawnictwo Literackie.

Mal'dzìs, Adam. (2010). Žyccë ì ǔznâsenne Uladzimira Karatkeviča. Partrèt pis'mennika i čalaveka: litaraturaznaǔčae èsè. Mìnsk: Lìtaratura ì Mastactva. [Мальдзіс, Адам. (2010). Жыциё і уззясенне Уладзіміра Караткевіча. Партрэт пісьменніка $і$ чалавека: літаратуразнаўчае эсэ. Мінск: Літаратура і Мастацтва].

b) Book with several authors: Bazylow, Ludwik; Wieczorkiewicz, Paweł. (2005). Historia Rosji. Wrocław: Ossolineum.

c) Reference of chapter in a book: Jurkowski, Roman. (2001). „W epoce defensywy narodowej”. Działalność i poglądy społeczno-polityczne Edwarda Woyniłłowicza w latach 1878-1909. In: Marian Mroczko (ed.). Polska i Polacy. Studia z dziejów polskiej myśli i kultury politycznej XIX i XX wieku (pp. 67-89). Gdańsk: Wydawnictwo Uniwersytetu Gdańskiego.

Saevič, Mìhal. (2016). Formy nazvaǔ žonak u naraǔskìh belaruskìh gavorkah Belastoččyny ǔ mìnulym ì sënnâ. In: İryna Bagdanovìc, Maryna Svìstunova (eds.). Belaruska-pol'skiâ moǔnyâ, litaraturnyâ, gìstaryčnyâ ì kul'turnyâ suvâzì (pp. 174-183). Mìnsk: BDU. [Саевіч, Міхал. (2016). Формы назваў жонак у нараўскіх беларускіх гаворках Беласточчыны ў мінулым і сёння. У: Ірына Багдановіч, Марына Свістунова (рэд.). Беларуска-польскія моўныя, літаратурныля, гістарычныля і культурныя сувязі (с. 174-183). Мінск: БДУ].

d) Reference of edited book: Roszkowski, Wojciech; Kofman, Jan (eds). (2004). Stownik biograficzny Europy Środkowo-Wschodniej XX wieku. Warszawa: Oficyna Wydawnicza RYTM.

e) Reference of journal article, (all words in the journal title - except for articles, prepositions and coordinating conjunctions with fewer than 5 letters - should be capitalized; if the journal uses a separate numbering for its issues, write the issue number after the annual number, in parentheses and without italics), specify the page range: Korzeniowski, Mariusz. (2011). Z działalności kulturalno-oświatowej Polaków w Kijowie. Wrocławskie Studia Wschodnie, 15(1), pp. 65-89. 
Pobrane z czasopisma Studia Bia?orutenistyczne http://bialorutenistyka.umcs.pl Data: 26/04/2023 14:23:56

f) Reference of article with DOI number: Bagdanowicz, Irina. (2009). Polskojęzyczny wiersz Kraków Adeli z Ustronia jako klucz do ustalenia autorstwa poematu Macocha. Studia Białorutenistyczne, 9, pp. 149-163. DOI: http://dx.doi.org/10.17951/ sb.2015.9.147.

g) Reference of unpublished work: Radzikowski, Roman. (in press). Wizje przeszłości. Studia Białorutenistyczne.

h) Text from website: Woyno, Jacek. (2012). Materiaty archiwalne do dziejów I Korpusu Polskiego w Rosji 1917-1918. Taken from: http://archiwumcaw.wp.mil.pl/ biuletyn/b24/b24_1.pdf (accessed: 01.04.2016).

i) Work without author: Merriam-Webster's Collegiate Dictionary. (1993). Springfield, MA: Merriam-Webster.

j) Press publication - author of the publication or the title, year of publication, title of journal, numer of publication. Example: W Mińsku. (1917). Dziennik Miński, 16.

k) Archival materials - name of the archive, signature. Example: AAN, CKO Archiwum Akt Nowych, Centralny Komitet Obywatelski w Piotrogrodzie - 11. 


\section{Authors}

\section{MARIUSZ AUSZ}

Place of work: Poland; Lublin, Maria Curie-Skłodowska University; Faculty of Humanities

Academic rank/degree/post (position): dr hab., assistant professor

Specialty: history

Scientific interests/fields of study (research): history of $17^{\text {th }}-20^{\text {th }}$ centuries, Piarist education, didactics of history, genealogy

e-mail:m.ausz@poczta.umcs.lublin.pl

Selected publications:

1. Ausz, Mariusz. (2013). Odbudowa polskiej prowincji pijarów. Działalność wychowawczo-edukacyjna zakonu w latach 1873-1918. Lublin: Wydawnictwo UMCS.

2. Ausz, Mariusz; Puchowski, Kazimierz. (2018). Komisja Edukacji Narodowej 1773-1794. Szkoły w wydziale pijarskim. Seria: Komisji Edukacji Narodowej model szkoły i obywatela - koncepcje, doświadczenia i inspiracje. Warszawa: Polska Akademia Nauk.

3. Ausz, Mariusz. (2017). Szkoły pijarskie na Białorusi. Studia Białorutenistyczne, 11, s. 9-20.

4. Ausz, Mariusz. (2015/2016). Rycerki Krucjaty Eucharystycznej przy parafii katolickiej w Szczuczynie Nowogródzkim w latach 1936-1938. Rocznik Lubelskiego Towarzystwa Genealogicznego, VII, s. 189-204.

5. Ausz, Mariusz; Barnaś-Baran, Ewa. (2018). Sport w pijarskim gimnazjum im. Ks. Stanisława Konarskiego w Rakowicach w latach 1909-1939. Biuletyn Historii Wychowania, 38, s. 55-66.

\section{NINA BARSZCZEWSKA}

Place of work: Poland; Warsaw; University of Warsaw

Academic rank/degree/post (position): dr hab., professor (retired)

Specialty: Eastern Slavic linguistics

Scientific interests/fields of study (research): Belarusian language and dialects, issues of cultural and linguistic borderland, Belarusian emigration in reference to the native language

e-mail:nbarszcz@uw.edu.pl 
Selected publications:

1. Barszczewska, Nina. (2016). Język a świadomość narodowa na Podlasiu. Kulturowo-językowe dziedzictwo Podlasia. Opis socjolingwistyczny regionu na tle uwarunkowań historycznych. T. 1 (s. 19-150). Warszawa: Katedra Białorutenistyki UW.

2. Barszczewska, Nina; Chaustowicz, Mikałaj; Timoszuk, Mikałaj (ed.). (2016). Kulturowo-językowe dziedzictwo Podlasia. T. 1. Kulturowo-językowe dziedzictwo Podlasia. Opis socjolingwistyczny regionu na tle uwarunkowań historycznych; T. 2. Człowiek. Rodzina. Dom; T. 3. Twórczość ludowa. Warszawa: Katedra Białorutenistyki UW.

3. Barszczewska, Nina; Jankowiak, Mirosław. (2012). Dialektologia białoruska. Warszawa: Slawistyczny Ośrodek Wydawniczy.

4. Barszczewska, Nina. (2004). Беларуская эміграџыя - абаронца роднае мовы (Emigracja białoruska w obronie języka ojczystego). Warszawa: Katedra Filologii Białoruskiej UW.

5. Barszczewska, Nina; Głuszkowska, Jadwiga; Jasińska, Teresa; Smułkowa, Elżbieta. (1992). Słownik nazw terenowych pótnocno-wschodniej Polski. T. 1. $A-\mathrm{N}$; T. 2. O-Ż. (1995). T. 3. Indeks nazw gwarowych. (1995). Warszawa: Wydawnictwa Uniwersytetu Warszawskiego.

\section{MIKALAJ CHAUSTOWICZ}

Place of work: Poland; Warsaw; University of Warsaw, Department of Belarusian Studies

Academic rank/degree/post (position): prof. dr hab.

Specialty: Belarusian literature

Scientific interests/fields of study (research): Belarusian literature of the $18^{\text {th }}-19^{\text {th }}$ centuries

e-mail:m.khaustovich@uw.edu.pl

Selected publications:

1. Хаўстовіч, Мікола. (2001). Гісторыя беларускай літаратуры 30-40-х г2. ХІХ $\mathrm{cm}$. Мінск: БДУ.

2. Хаўстовіч, Мікола. (2003). Мастаикі метад Яна Баршчэўскага. Мінск: БДУ.

3. Хаўстовіч, Мікола. (2006). Айчынна здалёку і зблізку: Ігнацы Яикоўскі i Аляксандар Рыпінскі. Мінск 2006.

4. Хаўстовіч, Мікола. (2010). Шляхамі да беларускасиі: Нарысы, артыкуль, эсэ. Warszawa: UW.

5. Хаўстовіч, Мікола. (2014). Даследаванні і матэрыялы: Літаратура Беларусі XIX-пачатку XX стагоддзяў. Т. 1. Warszawa: UW. 


\section{GENADZ TSYKHUN (HENADZ CYCHUN; ГЕНАДЗЬ ЦЫХУН)}

Place of work: Belarus; Minsk; The National Academy of Sciences of Belarus; The Yakub Kolas Institute of Linguistics

Academic rank/degree/post (position): doctor of science; main researcher; Doctor Honoris Causa of the Sofia University of St. Klement of Ohrid, foreign member of the Macedonian Academy of Sciences and Arts

Specialty: Slavic linguistics

Scientific interests/fields of study (research): Bulgarian studies, Macedonian studies, Paleo-Slavic studies, areal linguistics, history of Slavic studies, Slavic bibliography; Polish-Belarusian-Lithuanian borderline in the field of language interconnections

e-mail: henadz.cychun@gmail.com

Selected publications:

1. Цыхун, Генадзь. (2018). Прастора мовы. Моўныя сувязі. Гісторыя слой: выбраныя працы. Уклад. Яўгенія В. Волкава. Мінск: Беларуская навука.

2. Цыхун, Генадзь. (2012). Выбраныя пращы: беларусістыка, славістыка, арэальная лінгвістыка. Мінск: Беларуская навука.

3. Ц Цыхун, Генадзь. (1998). Славянскія мовы у святле экалінгвістыкі. ХІІ Міжнародны з'езд славістаў. Даклады. Мінск: Беларускі камітэт славістаў.

4. Ц Цыхун, Генадзь. (1988). Арэальная тыпалогія славянскіх моў: прынцыпы i напрамкі даследавання. Даклад на Х Міжнар. з'ездзе славістаў. Мінск: Навука і тэхніка.

5. Цыхун, Геннадий. (1981). Типологические проблемы балканского языкового ареала. Минск: Наука и техника.

\section{MONIKA FAMIELEC}

Place of work: Poland; Bydgoszcz; Kazimierz Wielki University; Institute of Modern Languages and Applied Linguistics

Academic rank/degree/post (position): dr; senior lecturer

Specialty: linguistics

Scientific interests/fields of study (research): East Slavic onomastics, Polish-East Slavic borderland, Polish-Russian and Russian-Polish contrastive linguistics, Russian-Polish lexicography

e-mail:monikafa@ukw.edu.pl

Selected publications:

1. Famielec, Monika. (2018). Урбанонимы города Бреста ХХ века. Bydgoszcz: Wydawnictwo Uniwersytetu Kazimierza Wielkiego.

2. Famielec, Monika. (2016). Эргоурбанонимное пространство города Бреста (на примере наименований салонов красоты). В: Ольга В. Perehod (рэд.). Славянские языки: системно-описательный и социокультурный аспекты исследования. Сборник научных трудов VII Международной 
научной конференции в двух частях. Т. 1 (с. 231-236). Брест: БрГУ имени А. С. Пушкина.

3. Famielec, Monika. (2016). Урбанонимная система межвоенного Бреста-над-Бугом. Studia Wschodniostowiańskie, 16, s. 193-205.

4. Famielec, Monika. (2016). Kreacje nazewnicze trójmiejskich osiedli mieszkaniowych. Biatostockie Archiwum Językowe, 16, s. 95-107.

5. Famielec, Monika. (2015). Память города - следы Великой Отечественной войны в названиях брестских улиц. Białorutenistyka Białostocka, 7, s. 395-405.

\section{GUN-BRITT KOHLER}

Place of work: Germany; Oldenburg; Carl von Ossietzky University of Oldenburg; Faculty of Linguistics and Culturology; Institution of Slavic Studies

Academic rank/degree/post (position): professor, doctor of science

Specialty: Slavic literary study

Scientific interests/fields of study (research): Slavic literature of the $19^{\text {th }}-21^{\text {st }}$ centuries, (Belarusian, Russian, Polish and Croatian), history of literature, theory of literature, small literature, the relationships between literature and philosophy

e-mail: gun.b.kohler@uni-oldenburg.de

Selected publications:

1. Kohler, Gun-Britt. (2003). Boris de Schloezer (1881-1969). Wege aus der russischen Emigration. Köln: Böhlau.

2. Kohler, Gun-Britt (Hg.). (2010). Blickwechsel. Perspektiven der slavischen Moderne. Wien/München/Berlin: Kubon\&Sagner (= Wiener Slawistischer Almanach Sonderband 78).

3. Kohler, Gun-Britt; Navumenka, Pavel; Grüttemeier, Ralf (Hg.). (2012). Kleinheit als Spezifik. Beiträge zu einer feldtheoretischen Analyse der belarussischen Literatur im Kontext, kleiner" slavischer Literaturen. Oldenburg: bis-Verlag (= Studia Slavica Oldenburgensia 20).

4. Колер, Гун-Бритт; Науменко, Павел. (2013). Аспекты и стратегии институциональной и эстетической автономизации в «малых» литературах (на материале белорусской литературы первой трети XX ст.). У: Колер, ГунБритт; Науменко, Павел (ред.). Белорусская литература как модель развития «малых» (славянских) литератур. Материалы к тематическому блоку на XV Международном съезде славистов (Минск, 20.-27.08.2013) (с. 7-90). Минск: Бизнесофсет.

5. Kohler, Gun-Britt. (2019). Feldgrenzen, Dissimilation und das Ringen um kulturelles Kapital. Selbst- und reziproke Fremdkonzeptualisierungen polnischer und belarussischer Literatur zu Beginn des 20. Jh. Die Welt der Slaven. Internationale Halbjahresschrift für Slavistik, 64/1, s. 34-66. 


\section{IRINA LAPPO}

Place of work: Poland; Lublin; Maria Curie-Skłodowska University; Faculty of Humanities

Academic rank/degree/post (position): dr hab., associate professor

Specialty: Slavic literature studies, theatre studies

Scientific interests/fields of study (research): Slavic drama and theatre of the $20^{\text {th }}$ and $21^{\text {st }}$ centuries

e-mail: irina.lappo@poczta.umcs.lublin.pl

\section{Selected publications:}

1. Lappo, Irina. (2005). Konfrontacje z tradycją: polska recepcja teatru białoruskiego. Acta Albaruthenica, 5, s. 78-89.

2. Lappo, Irina. (2005). Stereotyp Polaka i jego profilowanie w białoruskim kręgu językowo-kulturowym. Etnolingwistyka, 17, s. 113-143.

3. Lappo, Irina. (2007). Mrożek à la russe. Teatralna recepcja dramaturgii Stawomira Mrożka w rosyjskim kręgu językowo-kulturowym. Lublin: UMCS.

4. Lappo, Irina. (2009). Gdzie ten samowar? Stereotyp Rosjanina a odbiór Czechowa w Polsce. Dialog, 9, s. 60-79.

5. Lappo, Irina. (2010). Czechow w teatrze polskim. Lublin: UMCS.

\section{ULADZIMIR LOBACН (УЛАДЗІМIP ЛОБАЧ)}

Place of work: Belarus; Polotsk State University; Department of History and Tourism Academic rank/degree/post (position): doctor of historical sciences, docent, professor of the department

Specialty: ethnography, ethnology and anthropology

Scientific interests/fields of study (research): military and historical anthropology, sacred geography, sorcery and magic

e-mail: u.lobach@pdu.by / nordic972@gmail.com

Selected publications:

1. Лобач, Уладзімір. (2013). Міф. Прастора. Чалавек: беларускі традыцыйны ландшафт у семіятычнай перспектыве. Мінск: Тэхналогія.

2. Лобач, Уладзімір. (2014). Феномен вайны ў міфапаэтычнай карціне свету беларусаў. У: Беларускі фальклор: матэрыялы і даследванні. Навуковы зборнік. Bып. 1 (с. 58-91). Мінск: Навука.

3. Lobačius, Uladzimeras. (2015). Archeologiniai paminklai tradiciniame liaudies pasaulèvaizdyje (Baltarusijos - Rusijos paribys). Liaudies kultūra, 5, pp. 47-52.

4. Лобач, Уладзімір; Валодзіна, Таццяна. (2016). Святыя крыніцы Беларусі. Мінск: Беларуская навука.

5. Лобач, Уладзімір. (2019). Вясковыя святыні Беларусі і савецкая ўлада: вандалізм і святатацтва ў антрапалагічным вымярэнні. Веснік ПДУ. Серыя А. Гуманітар. Навукі, 1, с. 2-12. 


\section{SERGE MINSKEVICH (СЕРЖ МIHCКЕВIЧ; СЯРГЕЙ МIHСКЕВIЧ)}

Place of work: Belarus; Minsk; The National Academy of Sciences of Belarus; The Yanka Kupala Institute of Literature Studies

Academic rank/degree/post (position): candidate of philology sciences

Specialty: Belarusian literary criticism

Scientific interests/fields of study (research): comparative studies, translation studies, versification, romanticism, Mickiewiczology

e-mail: nasb@presidium.bas-net.by

Selected publications:

1. Minskiewicz, Sierż. (2015). Евгений Онегин А. Пушкіна ў перакладах А. Дудара і А. Куляшова. У: Матэрыялы Рэспубліканскай навукова-практычнай канферэнщылі (да 90-годдзя з дня нараджэння І.Я. Навуменкі), Мінск, 26-27 лютага 2015 г. (с. 411-417). Мінск: Права і эканоміка,.

2. Мінскевіч, Серж. (2016). Параўнальна-супастаўляльны аналіз перакладаў санета Максіма Багдановіча Паміж пяскоў егіпеикай зямлі на рускую мову. У: Першы міжнародны навуковы кангрэс беларускай культуры (с. 463-468). Мінск: Права і эканоміка.

3. Мінскевіч, Серж. (2016). Ян Баршчэўскі - Адам Міцкевіч: творчыя паралелі, інтэртэкстуальнасць. У: Ігар Л. Капылоў (ред.). Беларуска-польскія культурна-моўныя уззаемадачыненні: ад гісторыі да сучасначі: зб. навук. apm. (с. 378-386). Мінск: Беларуская навука.

4. Мінскевіч, Серж. (2017). Еўрапейскі санет у беларускіх перакладах. У: Паэтыка літаратурных сувязей (с. 425-521). Мінск: Беларуская навука.

5. Мінскевіч, Серж. (2018). Параўнальны аналіз перакладаў 90-га санета Уільяма Шэкспіра на беларускую мову. Полымя, 7, с. 113-124.

\section{IVAN NOVIK (IBAH HOBIK)}

Place of work: Belarus; Minsk; The National Academy of Sciences of Belarus; Institute of Philosophy

Academic rank/degree/post (position): candidate of philosophy science

Specialty: philosophy

Scientific interests/fields of study (research): history of philosophy and social thought in Belarus in the 20-30s of the $20^{\text {th }}$ century, methodology of researching the history of philosophy

e-mail: novik.jan@gmail.com

\section{Selected publications:}

1. Новік, Іван. (2013). Апалагетыка, пошукі саюзнікаў і барацьба за артадоксію ў 1920-я гады. Роля беларускіх савецкіх філосафаў у паўставанні канону савецкага марксізму. Палітычная сфера, 21 (2), с. 29-54. 
2. Новік, Іван. (2018). Тэмпаральная семантыка ў эсэ І. Абдзіраловіча „Адвечным шляхам". У: Философские исследования. Сборник научных трудов, вып. 5 (с. 343-357). Мінск: Беларуская навука.

3. Новік, Іван. (2018). Філасофія «крытычнага аптымізму» Уладзіміра Самойлы. Białorutenistyka Białostocka, 10, s. 355-394.

4. Новік, Іван. (2019). Паэзіс калектывізацыі: наратыўныя контуры трагедыі. Тэрмапіль, 23, с. 235-264.

5. Новик, Иван. (2019). Понятия как «реккурентные элементы» дискурса: подход к истории концептуального в «Археологии знания» Мишеля Фуко. Логос, 29(2), с. 126-150.

\section{RYSZARD RADZIK}

Place of work: Poland; Warsaw; The Maria Grzegorzewska University; Institute of Philosophy and Sociology

Academic rank/degree/post (position): prof. dr hab.

Specialty: sociology

Scientific interests/fields of study (research): sociology of the nation, nation-building processes in Central and Eastern Europe, especially the formation of Belarusian society and nation in the last two centuries

e-mail: rradzik@aps.edu.pl

Selected publications:

1. Radzik, Ryszard. (2000). Między zbiorowościa etniczna a wspólnota narodowa. Biatorusini na tle przemian narodowych w Europie Środkowo-Wschodniej XIX stulecia. Lublin: Wydawnictwo UMCS.

2. Radzik, Ryszard. (2002, 2003, 2004). Kim sq Białorusini?. Toruń: Wydawnictwo Adam Marszałek.

3. Radzik, Ryszard. (2012). Biatorusini-między Wschodem a Zachodem. Lublin: Wydawnictwo UMCS.

4. Radzik, Ryszard. (2016). Rosyjski imperializm wspólnotowy. Trójjedyny naród ruski w badaniach socjologicznych. Lublin: Wydawnictwo UMCS.

5. Радзік, Рышард. (2017). Вакол ідэнтычнасиі беларусай, пер. $з$ польск. мовы С. Петрыкевіч, навук. рэд. Генадзь Сагановіч (Бібліятэка часопіса “Беларускі Гістарычны Агляд”). Мінск: Лімарус.

\section{ELŻBIETA SMULKOWA}

Place of work: Poland; Warsaw; University of Warsaw

Academic rank/degree/post (position): prof. dr hab., professor (retired)

Specialty: Slavic linguistics

Scientific interests/fields of study (research): Belarusian language and its dialects, comparative Slavic linguistics, Polish-Belarusian-Lithuanian border zone language relationships, social and ethno linguistics 
Selected publications:

1. Smułkowa, Elżbieta; Skarżyński, Michał (opr.). (2018). Materiały do dziejów polskiego językoznawstwa III. Korespondencja Kazimierza Nitscha i Antoniny Obrębskiej-Jablońskiej 1925-1958. Cz. 1. 1925-1945; Cz. 2. 1946-1958. Kraków: Księgarnia Akademicka.

2. Smułkowa, Elżbieta. (2016). Moje pogranicza w historii, języku $i$ wspomnieniach. Warszawa: Instytut Slawistyki PAN.

3. Smułkowa, Elżbieta (red.). (2011). Brasławszczyzna. Pamięć i współczesność. T. 1. Historia regionu. Charakterystyka socjolingwistyczna. Świadectwo mieszkańców. Warszawa: Wydawnictwa Uniwersytetu Warszawskiego.

4. Smułkowa, Elżbieta. (2002). Białoruś i pogranicza. Studia o języku i społeczeństwie. Warszawa: Wydawnictwa Uniwersytetu Warszawskiego.

5. Smułkowa, Elżbieta. (1978). Studia nad akcentem języka białoruskiego. Rzeczownik. Warszawa: Wydawnictwa Uniwersytetu Warszawskiego.

\section{VOLGA SAВАLEUSKAYА (ОЛЬГА СОБОЛЕВСКАЯ)}

Place of work: Belarus; Grodno; Belarusian Institute of Law (Grodno Branch); Department of Social Humanitarian and Linguistic Disciplines

Academic rank/degree/post (position): candidate of cultural studies

Specialty: history of Belarus, Judaic studies

Scientific interests/fields of study (research): history of the Jews, the features of settlement (late $18^{\text {th }}$ - early $20^{\text {th }}$ century)

Selected publications:

1. Соболевская, Ольга; Гончаров, Владимир. (2005). Евреи Гродненщины: Жизнь до Катастрофыл. Донецк: Норд-Пресс.

2. Соболевская, Ольга. (2012). Повседневная жизнь евреев Беларуси в конще XVIII- 1 пол. ХIX века. Гродно: ГрГУ.

3. Sabaleuskaya, V. A. (2006). Changing Conceptions of Leisure among the Jews of Western Belarus' at the End of the $19^{\text {th }}$ Century. East European Jewish Affairs, 2, pp. 127-140.

4. Соболевская, Ольга. (2016). О “человеке путешествующем”: миграционный контекст истории евреев Гродненской губернии (XIX-нач. XX в.). Dialog Stowiańsko-Żydowski. Studia, c. 104-119.

5. Соболевская, Ольга. (2017). Еврейские праздники XIX - начала XX в. как способ мемориализации прошлого. The journal of ethnology and culturology, 21, pp. 39-44. 


\section{ADAM STANKEVIČ}

Place of work: Lithuania; Vilnius, The Lithuanian Institute of History; Department of the History of the Grand Duchy of Lithuania

Academic rank/degree/post (position): $\mathrm{PhD}$

Specialty: history

Scientific interests/fields of study (research): judiciary in the Grand Duchy of Lithuania in $18^{\text {th }}$ century, history of advocacy

e-mail: adam.stankevic@istorija.lt

Selected publications:

1. Stankevič, Adam. (2018). Lietuvos Vyriausiojo Tribunolo veikla XVIII amžiaus antroje pusejje. Vilnius: Lietuvos istorijos institutas.

2. Stankevič, Adam. (2016). The Debate over the Legacy of Hrodno Flag-Bearer Stanisław Isaykowski. In: Jolanta Karpavičienè (ed). History of the Lithuanian Notariat (p. 95-110). Vilnius: R. Paknio leidykla.

3. Stankevič, Adam. (2017). Antano Klemento kūrybinès aspiracijos. Senoji Lietuvos literatūra, 43, s. 214-249.

4. Stankevič, Adam. (2018), Działalność Trybunału Litewskiego w Grodnie (w latach 1775-1791). У: А. Радзюк, В. Галубовіч (рэд.). Grodnae et orbi. Гарадскія супольнасиі і гарадское асяроддзе XIV-XX cmст. Матэрыяль міжнароднай навуковай канференщыі (Гародня, 4-5 лістапада 2017 г.) (с. 92-101). Мінск: Выдавец А. М. Янушкевіч.

5. Stankevič, Adam. (2018). Teisminių dokumentų įvardijimai Trečiajame Lietuvos Statute ir jų raidos bruožai. Lietuvos istorijos metraštis, 2, s. 31-53.

\section{ALENA SUMКО (АЛЕНА СУМКО)}

Place of work: Belarus; Polotsk State University; Department of History and Tourism Academic rank/degree/post (position): candidate of historical sciences, docent Specialty: history

Scientific interests/fields of study (research): the history of everyday life, oral history, life support system of the Belarusian village, economic anthropology, socio-cultural stereotypes

e-mail: sumko_elena@mail.ru

Selected publications:

1. Сумко, Елена. (2018). Восприятие сельским населением сотрудников милиции как редставителей права и законности (по материалам устной истории Северного Подвинья Беларуси). History: sources and people, 21, с. 373-381.

2. Сумко, Алена. (2018). Абмен і гандаль у беларускім традыцыйным грамадстве. Вестн. Полои. гос. ун-та, 1, с. 54-58. 
3. Сумко, Алена. (2018). Эканамічны і соцыякультурны аспект самагонаварэння ў сельскім ландшафце Паўночнай Беларусі ў другой палове 1940х - 1960-х гг. Вестн. Полои. гос. ун-та, 9, с. 127-135.

4. Сумко, Елена. (2019). Послевоенная действительность в воспоминаниях жителей Западной Витебщины (по материалам полевых исследований. History: sources and people, 22, c. 273-280.

5. Сумко, Алена. (2019). Легальныя і крымінальныя спосабы жыццязбеспячэння. Вестн. Полоч. гос. ун-та, 1, с. 55-62.

\section{ROMAN WYSOCKI}

Place of work: Poland; Lublin; Maria Curie-Skłodowska University; Faculty of Humanities

Academic rank/degree/post (position): dr hab., assistant professor

Specialty: history

Scientific interests/fields of study (research): Ukrainian political thought, national processes and national movements, history of Ukraine, Polish-Ukrainian and Polish-Belarusian relations

e-mail: wysocki@poczta.umcs.lublin.pl

\section{Selected publications:}

1. Wysocki, Roman. (2018). W poszukiwaniu modelu narodowościowej reprezentacji. Sprawa udziału przedstawicieli środowisk ukraińskich $\mathrm{w}$ pracach Rady Narodowej Rzeczypospolitej Polskiej w latach 1939-1945. W: Zbigniew Girzyński, Paweł Ziętara (red.). Depozyt Niepodległości. Rada Narodowa Rzeczypospolitej Polskiej na uchodźstwie 1939-1991) (s. 87-114). Toruń: Wydawnictwo Adam Marszałek.

2. Wysocki, Roman. (2017). Rola „obcego” w ideologii integralnego nacjonalizmu. Próba analizy porównawczej na przykładzie publicystyki Romana Dmowskiego i Dmytra Doncowa. W: Małgorzata Karwatowska, Robert Litwiński, Adam Siwiec (red.). Obcy / Inny. Analiza przypadków (s. 307-319). Lublin: Wydawnictwo UMCS.

3. Wysocki, Roman. (2017). Delegalizacja Białoruskiej Włościańsko-Robotniczej Hromady w 1927 r. w świetle dokumentów brytyjskiego Foreign Office. Białoruskie Zeszyty Historyczne, 47, s. 219-242.

4. Wysocki, Roman. (2018). Redefinicja „narodowego bohaterstwa” między polityką a nauką. Szkic o współczesnych dyskusjach wokół „legendy Romana Dmowskiego". Historyka. Studia Metodologiczne, 48, s. 329-345. 


\section{SIARHIEJ ZAPRUDSKI (СЯРГЕЙ ЗАПРУДСКI)}

Place of work: Belarus; Minsk; Belarusian State University in Minsk, Faculty of Philology

Academic rank/degree/post (position): doctor of science, docent

Specialty: Slavic linguistics

Scientific interests/fields of study (research): history of the Belarusian literary language, history of the Belarusian literary studies, language relationships, language policy, social language psychology, foreign Belarusian studies

e-mail: zaprudskiSM@bsu.by

\section{Selected publications:}

1. Запрудскі, Сяргей. (2018). „Сербскі слоўнік” Вука Караджыча і „Слоўнік беларускай мовы” Івана Насовіча: падабенствы і адрозненні. Зборник Матице српске за славистику, 93, с. 127-144.

2. Zaprudski, Siarhiej. (2014). Zur öffentlichen Diskussion der weißrussischen Sprachkultur, zum Aufkommen des Terminus ,Trasjanka“ und zur modernen Trasjankaforschung. In: G. Hentschel, O. Taranenko, S. Zaprudski (hrsg.). Trasjanka und Suržyk - gemischte weißrussisch-russische und ukrainischrussische Rede. Sprachlicher Inzest in Weißrussland und der Ukraine? (s. 119-141). Peter Lang Verlag.

3. Запрудскі, Сяргей. (2013). Беларускае мовазнаўства і развіщцё беларускай літаратурнай мовы: 1920-1930-я гады. Мінск: БДУ.

4. Запрудскі, Сяргей. (2012). Павал Ёзаф Шафарык як беларусіст (на матэрыяле „Гісторыі славянскай мовы і літаратуры ва ўсіх дыялектах” 1826 г.). Studia Slavica Academiae Scientiarum Hungaricae, 57(1), c. 143-159.

5. Zaprudski, Siarhiej. (2007). In the grip of replacive bilingualism: the Belarusian language in contact with Russian. International Journal of the Sociology of Language. 183, pp. 97-118.

\section{PIOTR ZLOTKOWSKI}

Place of work: Poland; Lublin; Maria Curie-Skłodowska University, Faculty of Humanities

Academic rank/degree/post (position): dr, assistant professor

Specialty: Slavic linguistics

Scientific interests/fields of study (research): Slavic onomastics, language history, paleography and neography

e-mail: pzlotko@poczta.umcs.lublin.pl

Selected publications:

1. Złotkowski, Piotr. (2017). Antroponimia historyczna mieszczan i chtopów Brańska i okolic w ujęciu statycznym i dynamicznym. Lublin: Wydawnictwo Uniwersytetu Marii Curie-Skłodowskiej. 
Pobrane z czasopisma Studia Bia?orutenistyczne http://bialorutenistyka.umcs.pl Data: 26/04/2023 14:23:56

2. Złotkowski, Piotr. (2016). Świadomość użytkowników forów genealogicznych w zakresie nominacji antroponimicznej. Prace Językoznawcze, 18(3), s. 219-236.

3. Złotkowski, Piotr. (2016). Nazwy młynów i osad młyńskich dawnego starostwa brańskiego. Studia Wschodniostowiańskie, 16, s. 345-364.

4. Złotkowski, Piotr. (2015). Происхождение рода Склодовских на основании малоизвестных исторических источников и новых ономастических сведений. Slavica, 44, s. 21-30.

5. Złotkowski, Piotr. (2014). O pochodzeniu nazwy uroczyska Kumat pod Brańskiem. Czyżby koniec legendy? Studia Białorutenistyczne, 8, s. 237-250. 